\title{
CNTs nanostructuring effect on the properties of graphite composite bipolar plate
}

\author{
S.R. Dhakate*, S. Sharma, N. Chauhan, R.K. Seth, R.B. Mathur
}

Carbon Technology Unit, Engineering Materials Division, National Physical Laboratory, CSIR, Dr. K. S. Krishnan Marg, New Delhi 110012 India

\begin{abstract}
A B S T R A C T
Intent of present investigation is to improve the properties of graphite-polymer composite bipolar plate by nanostructuring. This involves the incorporation of different vol.\% of multiwall carbon nanotubes (MWNTs) in graphite-polymer composite bipolar plate. It has been found that by inclusion of 1 vol.\% of MWNTs in graphite composite plate, the electrical and thermal conductivity of nanocomposite increased by $100 \%$. The thermal conductivity of nanocomposite plate increases from $1 \mathrm{~W} / \mathrm{m} \mathrm{K}$ to $13 \mathrm{~W} / \mathrm{m} \mathrm{K}$ in throughplane and in-plane from $25 \mathrm{~W} / \mathrm{m} \mathrm{K}$ to $50 \mathrm{~W} / \mathrm{m} \mathrm{K}$ at 1 vol.\% of MWNTs. This significant enhancement is due to the orientation of MWNTs in all the directions of composite, positive synergistic effect of MWNTs and heat transfer along the axis directions. However, bending strength of nanocomposite increases by $25 \%$ and maximum augmentation is in case of 1 vol.\% of MWNTs. The improvement in conductivity of nanocomposite plate is due to an increase in the electron transfer ability within the composite plate which influences the I-V performance of ultimate fuel cell. These observations confirm that the optimal content of MWNTs is 1 vol.\%, in graphite-polymer composite.
\end{abstract}

\section{Introduction}

Graphite has number of unique properties such as good electrical conductivity, corrosion resistance and high thermal conductivity [1]. These properties allow graphite to be used in various electrochemical applications [2]. Graphite is a crystalline form of carbon where the atoms are bonded in basal plane and with weak Vander Waal forces between the layers which are separated by a distance of $0.3345 \mathrm{~nm}$. Due to different nature of bonding in basal plane and the layers, graphite exhibits structural anisotropy and possesses highly directional properties e.g., thermal, mechanical and electrical conductivity.

The polymer electrolyte membrane fuel cell (PEMFCs) exhibits the most promising alternative source of energy for a variety of portable electronic devices, stationary and vehicle applications [3,4]. To generate useful current and voltage, individual single fuel cells are connected in series to form stack of cells. Thus, bipolar plates being one of the key components of PEMFCs must not only exhibit high electrical conductivity as a current collector but also should have adequate mechanical strength to bear the clamping force while the stack is assembled. Traditionally, the most commonly used material for bipolar plates is graphite because it provides excellent corrosion resistance, low bulk density and high electrical conductivity $[5,6]$. The graphite composite plate developed from the graphite particles with polymeric matrices have graphite particles mostly oriented in $x-y$ direction (in-plane) as compared to z-direction (throughplane). Therefore, these composites retain the characteristic of graphite flakes and anisotropic properties and hence, responsible for large difference in the value of through plane 
and in-plane conductivity [7]. The particle size of natural graphite also plays a significant role in determining overall characteristics of graphite-polymer composite bipolar plate. The bigger particle size based composite plates have higher electrical and thermal properties but lack good mechanical properties. However, the smaller particle size based plates have higher mechanical and poor electrical properties $[8,9]$.

To overcome the problem of poor electrical and thermal properties of smaller particle based graphite-polymer composite bipolar plates, there is a need to add some fraction of bigger particles or incorporate highly conducting phase of nanosize. The nanosize particles, whiskers or fibers can be oriented randomly in all the three directions of composite plates. Therefore, nanostructuring approach is used in this investigation, this involves the application of conductive MWNTs in small vol.\% in graphite-polymer composite plates. The MWNTs are very fascinating and smallest form of carbon material that attracted considerable attention of researcher since their first observation by lijima [10]. The MWNTs are considered to be perfect whiskers with exceptional tensile strength and modulus of individual CNT are up to $150 \mathrm{GPa}$ and $1 \mathrm{TPa}$, respectively [11-13]. In addition to special electrical properties, unusually high thermal conductivity, high aspect ratio and lightweight enable the MWNTs to reinforce them in to polymer composites $[14,15]$. In the present study, to improve the properties of bipolar plates, different volume fraction of MWNTs are incorporated in graphite-polymer composite bipolar plates.

\section{Experimental}

In this study natural graphite of purity $95-96 \%$ and particle of size $50 \mu \mathrm{m}$ was used as reinforcement procured from Shanker Graphites and Chemicals, Kanchan House, Karam Pura, New Delhi (India). The thermosetting phenolic resin in powder form was used as a matrix precursor, procured from Pheno Organic Private Limited, Azadpur, New Delhi.

Multiwall carbon nanotubes MWNTs synthesized by CVD method in the laboratory [16] and it was used as one of the filler for improving the properties of graphite-polymer composite. Initially MWNTs were ultrasonically dispersed in the toluene for 30 min to obtain mixture of MWNTs dispersed in the solvent. In the dispersed mixture of MWNTs and toluene, requisite amount of natural graphite powder added and this mixture ultrasonically mixed for $1 \mathrm{~h}$. Later on the mixture was dried at temperature $70-80^{\circ} \mathrm{C}$. The dried mixture with calculated amount of phenolic resin was ball milled for $3 \mathrm{hr}$ to obtain uniform mixture of all components. The composite plates of size $60 \mathrm{~mm} \times 20 \mathrm{~mm} \times 0.4 \mathrm{~mm}$ were fabricated using mixed compound by compression molding technique [7]. These composite contains $65 \%$ natural graphite and $35 \%$ polymeric resin.

Surface (shore) hardness of the bipolar plates was measured by means of a Scleroscopic hardness tester obtained from Coats Machine Tool Co. Ltd. London [17].

The morphology of nanocomposite was studied by scanning electron microscope (SEM model LEO 440) in laboratory. The bending or flexural strength and modulus of composites were measured on universal INSTRON testing machine model
4411 as per ASTM-D790 procedure. Electrical conductivity of nanocomposite was measured by using four-probe technique. Kiethley 224 programmable current source was used for providing constant current (I). The voltage drop (V) in between two pinpoints with a span of $1.2 \mathrm{~cm}$ was measured by Keithley 197 A auto ranging microvolt DMM. The throughplane conductivity of bipolar plates were measured, using four-probe technique with applying uniform load $\left(100 \mathrm{Kg} / \mathrm{cm}^{2}\right)$ on all samples, schematic diagram shown in Fig. 1.

The thermal conductivity of composites were measured by laser flash method having xenon laser as a source in thermo flash line 2003 instrument (Anter Corporation, USA). In which test sample of size $12.7 \mathrm{~mm} \times 12.7 \mathrm{~mm} \times 3 \mathrm{~mm}$ and testing was performed in vacuum. By laser flash method, thermal diffusivity and specific heat of each sample was measured at $25{ }^{\circ} \mathrm{C}$. The thermal conductivity then calculated from the equation, $\alpha=k / \rho . C p$, where $\alpha$ is the thermal diffusivity, $k$ is thermal conductivity, $C p$ is the specific heat and $\rho$ is density of the composite.

\section{Results and discussion}

Fig. 2 shows the SEM micrograph of MWNTs synthesized from CVD technique in the laboratory. It is observed that diameter of MWNTs varies between 50 and $100 \mathrm{~nm}$ and their length is in the order of few microns.

Fig. 3 shows the variation in bulk density and hardness of composite with increasing MWNTs content. The bulk density of the composite plates is influenced by the accumulation of MWNTs in the composite, at 1 vol.\% MWNTs bulk density decreases from $1.85 \mathrm{~g} / \mathrm{cc}$ to $1.78 \mathrm{~g} / \mathrm{cc}$ of nanocomposite. Further, on increasing the CNT content bulk density continuously decreases as an implication of low density of MWNTs as compared to natural graphite. However the hardness of bipolar plate decreases with increasing MWNTs contents in the composite plate composition. This might be due to the poor bonding of MWNTs with other constituents in composites.

Electrical conductivity of nanocomposite plate increases with increasing MWNTs content as shown in Fig. 4. A high in-plane electrical conductivity is an essential feature for PEMFC bipolar plates. A percolating conducting path is

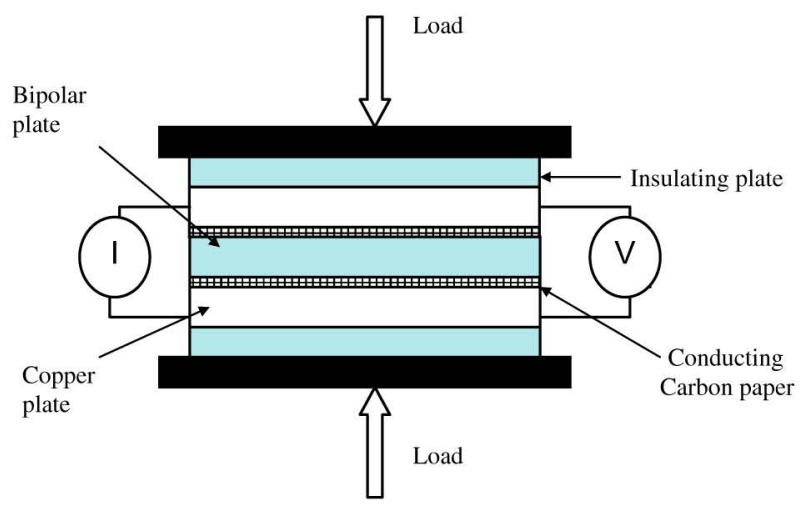

Fig. 1 - Schematic of through-plane conductivity measurement setup. 


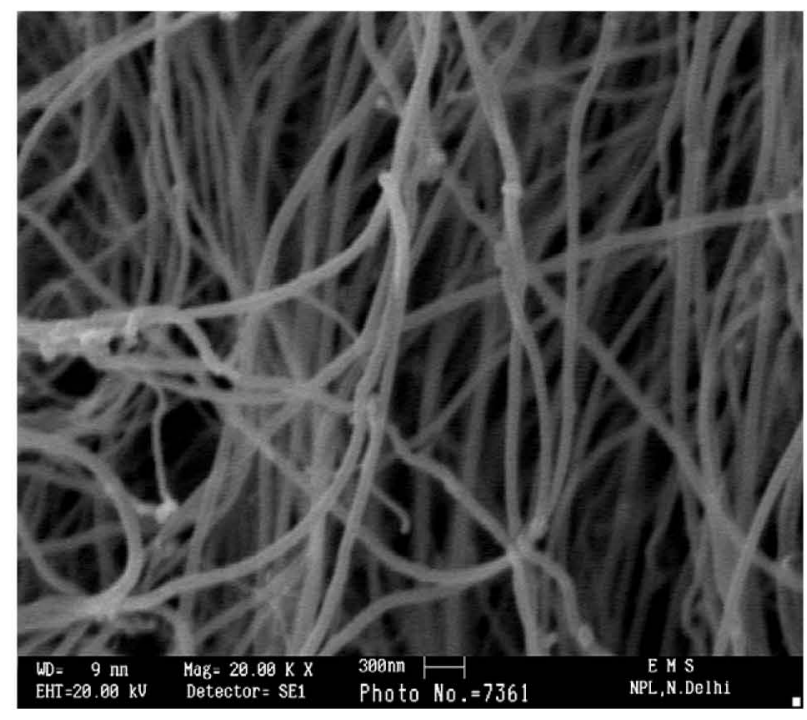

Fig. 2 - SEM of MWNTs synthesized by CVD.

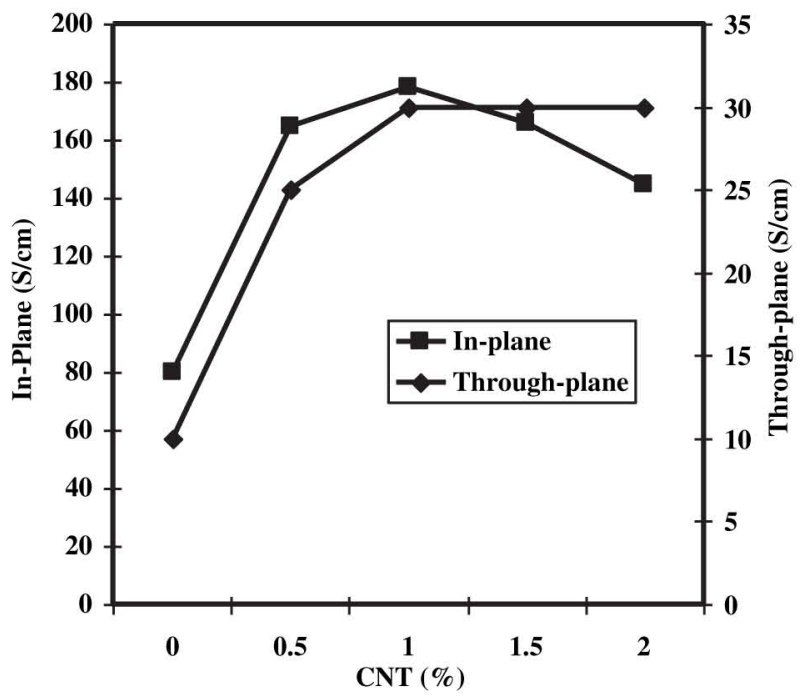

Fig. 4 - Electrical Conductivity (in-plane and throughplane)of composite plates with increasing MWNTs content in graphite-polymer composite.

hand, the value of through-plane conductivity is quite less as compared to in-plane conductivity. This is due to an anisotropic property of graphite particles. The through-plane conductivity of graphite-polymer composite is $8-10 \mathrm{~S} / \mathrm{cm}$ and on addition of MWNTs, through-plane conductivity increases to $25 \mathrm{~S} / \mathrm{cm}$ at $0.5 \mathrm{vol}$.\% MWNTs. On increasing MWNTs content, conductivity reaches at maximum value of $30 \mathrm{~S} / \mathrm{cm}$ at $1 \mathrm{vol} . \%$. The MWNTs form a percolating conducting path between graphite particles. On further increasing MWNTs content, appears saturation in the value of conductivity and this may be due to the agglomeration of MWNT in the composite.

The thermal conductivity is also a requisite property of bipolar plate for heat dissipation during the functioning of fuel cell stack which is operated above temperature $70^{\circ} \mathrm{C}$. In this study, thermal conductivity of composite plates is measured at ambient temperature. Fig. 5 shows the thermal conductivity of composite plates with increasing MWNTs content. In case of graphite-polymer composite, maximum thermal conductivity is achieved in-plane as compared to through-plane direction because maximum number of graphite particles is generally oriented in in-plane as compared to through-plane direction. Therefore, to improve the through-conductivity of the graphite composite bipolar plate, nanostructuring approach is adopted (i.e. different vol.\% of MWNTs incorporated in composite). The thermal conductivity of graphitepolymer composite, $25 \mathrm{~W} / \mathrm{m} \mathrm{K}$ is in-plane and $1 \mathrm{~W} / \mathrm{m} \mathrm{K}$ in through-plane. But, on the addition of 1 vol.\% of MWNTs, thermal conductivity of nanocomposite plates increases by $100 \%$ i.e., from 25 to $50 \mathrm{~W} / \mathrm{m} \mathrm{K}$. However, through-plane conductivity increases from $1 \mathrm{~W} / \mathrm{m} \mathrm{K}$ to $13 \mathrm{~W} / \mathrm{m} \mathrm{K}$. This significant enhancement in through-plane conductivity of nanocomposite is due to the MWNTs oriented in z-direction also. With increasing MWNTs content, conductivity does not increases which may be due to the agglomerated form of MWNTs and MWNTs/MWNTs interfaces limits thermal transport in the composite because of no medium to transfer
Fig. 3 - Bulk density and Hardness of composite plates with increasing MWNTs content in graphite-polymer composite.

necessary to achieve high electrical conductivity [18]. However, in graphite-polymer composite plate a layer of insulating polymer matrix with high electrical resistance along the congraphite only contributes to limited conductivity of the MWNTs content up to 2 vol.\%, the electrical conductivity
decreases up to $145 \mathrm{~S} / \mathrm{cm}$, although the value is much higher than that of the graphite-polymer composite. On the other

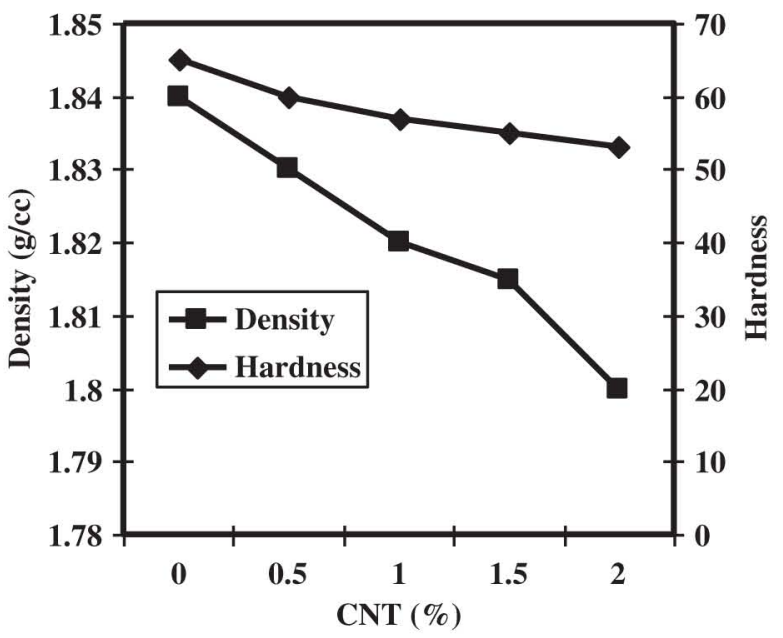




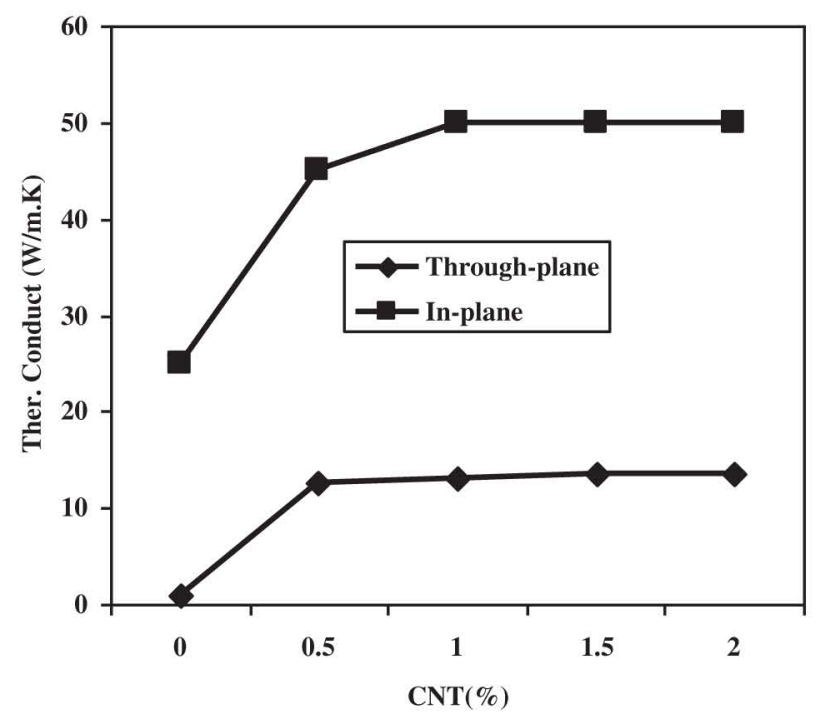

Fig. 5 - Thermal conductivity with increasing MWNTs vol.\% in graphite-polymer composites.

heat between MWNTs. The improvement in through-plane conductivity is interpreted in terms of positive synergistic effect of MWNTs and heat transfer along the axis of MWNTs.

In nanostructure graphite-polymer composites, MWNTs appear between graphite particles and not between individual layers of graphite, these MWNTs improve the percolation or thermal contact between graphite particles. This indicates that MWNTs effectively forms an additional conductive network in composites because of their smaller size. This can be interpreted in terms of positive synergistic effect between NG and MWNTs, on electrical and thermal conductivity. The positive synergistic effect can be explained on the basis of additional conductive pathway formed in the presence of MWNTs in between the NG particles which are oriented in all the directions. The intrinsic conductivity of NG and that of MWNTs is almost same ( around $10^{4} \mathrm{~S} / \mathrm{cm}$ ). However, MWNTs are one dimensional and transport of electron will take place in axial direction. MWNTs in between the NG acts

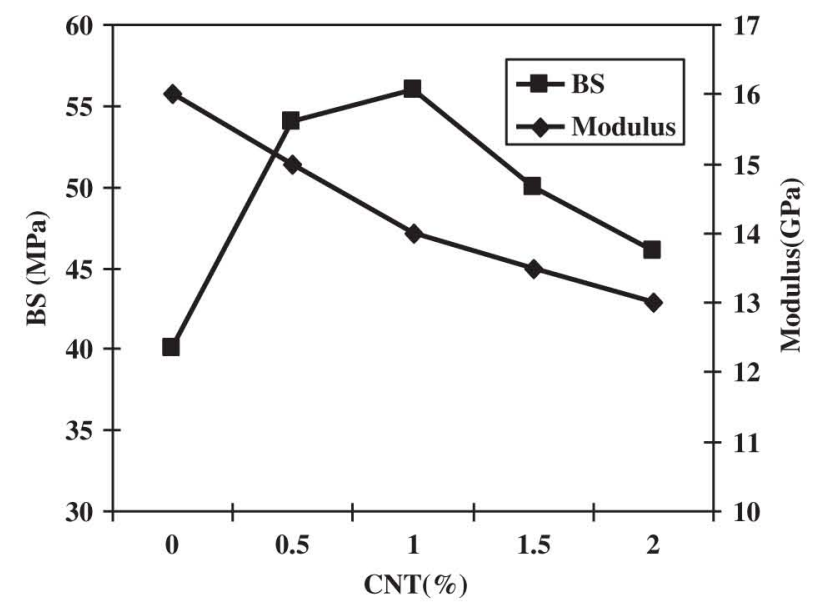

Fig. 6 - Bending strength and modulus with increasing MWNTs vol.\% in graphite-polymer composite.
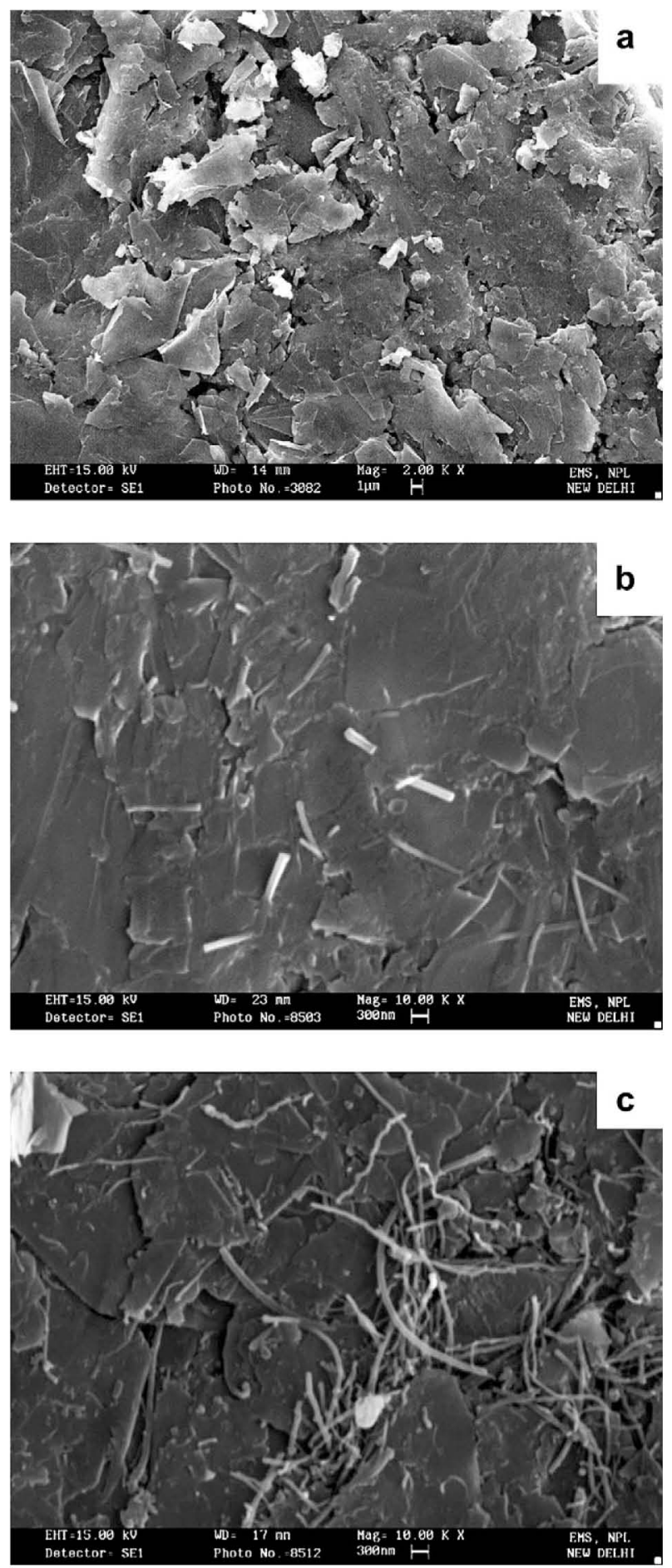

Fig. 7 - SEM micrograph of (a) graphite-polymer (b) nanocomposite with $1 \%$ MWNTs (c) nanocomposites with 2\% MWNTs.

like a bridge for electron mobility in all the directions and impart electrical conductivity in the composite. However, on increasing MWNTs content greater than 1 vol.\%, conductivity of composite decreases this can be due to the percolation threshold. The MWNTs are in agglomerated form in the composite due to its high surface area and its higher content which decreases the conduction path of electron because of 
Table 1 - Comparison of properties between commercial and CNT based composite bipolar plate.

\begin{tabular}{|c|c|c|c|c|c|}
\hline Properties & DOE [19] & SGL [20] & Schunk [21] & $\begin{array}{l}\text { Fuel cell } \\
\text { store [22] }\end{array}$ & $\begin{array}{c}\text { Bipolar plate with } \\
1 \% \mathrm{CNT}\end{array}$ \\
\hline Density $\left(\mathrm{g} \mathrm{cm}^{-3}\right)$ & $\sim 1.9$ & 1.97 & 1.90 & 1.90 & 1.82 \\
\hline \multicolumn{6}{|l|}{ Electrical conductivity $\left(\mathrm{S} \mathrm{cm}^{-1}\right)$} \\
\hline In plane ( $x-y$ direction) & $>100$ & $>100$ & $>100$ & $>100$ & 178 \\
\hline Through plane (z-direction) & $>20$ & $>20$ & $>20$ & 20 & 30 \\
\hline Flexural strength (MPa) & $>25$ & 40 & $>40$ & $>40$ & 56 \\
\hline Modulus (GPa) & 10 & 14 & 10 & 10 & 14 \\
\hline Shore hardness & $>50$ & - & 60 & 52 & 57 \\
\hline Thermal conductivity $\left(\mathrm{W} / \mathrm{mK}^{-1}\right)$ & 20 & 20 & 20 & - & 50 \\
\hline
\end{tabular}

multiple networks of MWNTs, MWNTs/MWNTs interfaces limits thermal transport in the composite. This clearly brings out that the optimum content of MWNTs in graphite-polymer composite is $1 \mathrm{vol} \%$ in the present study.

The bending strength of graphite-polymer composite is $40-45 \mathrm{MPa}$ and on addition of $0.5 \mathrm{vol} \%$ of MWNTs, strength increases up to $55 \mathrm{MPa}$ and $60 \mathrm{MPa}$ at 1.0 vol.\% of MWNTs in composite as shown in Fig. 6. Further on increasing the MWNTs content, strength does not increases much. However, at 2 vol.\% of MWNTs, strength of nanocomposite decreases. This can be due to higher content of MWNTs which are in agglomerated form and poor bonding of MWNTs with other constituents in the composites. Over all it is found that, strength of composites is not greatly improved on the addition of MWNTs. This is also supported from the data of flexural modulus of nanocomposite. The modulus decreases as a consequence of change in mode of fracture behavior of composite.

Fig. 7 shows the SEM micrograph of graphite-polymer and MWNTs nanostructure composites. Fig. 7a, in which the graphite flakes are mostly oriented in xy-plane and well bonded with each other in the presence of polymer matrix. On nanostructuring of graphite-polymer composite with 1 vol.\% MWNTs are well dispersed in the composite (Fig. 7b). With increasing MWNTs contents in composite, MWNTs are in agglomerated form in the nanocomposite (Fig. 7c), as

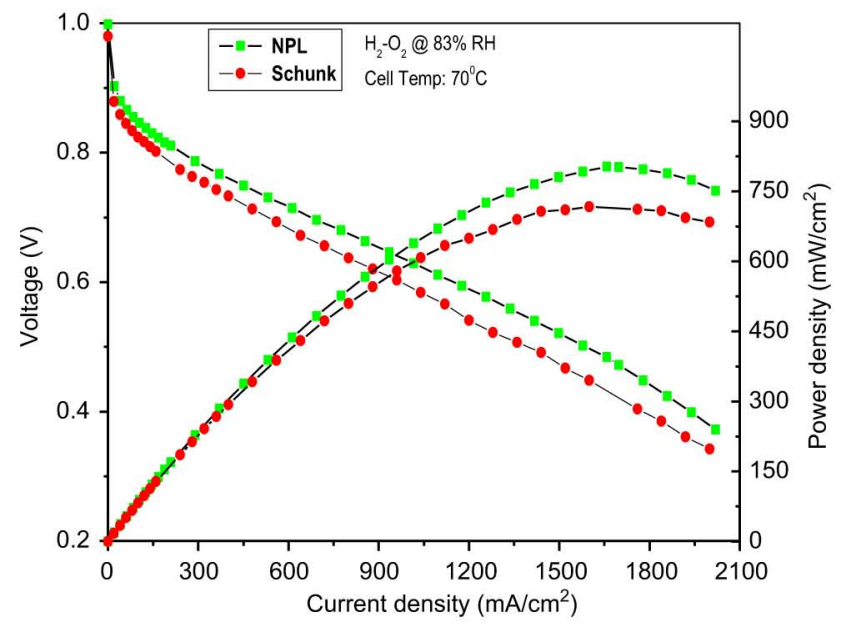

Fig. 8 - I-V performance of composite bipolar plate with $1 \%$ of MWNTs compared with commercial schunk bipolar plate. a consequence decrease in electrical and thermal properties of bipolar plate.

Table 1 compares the properties of commercial bipolar plate with composite plates developed in the present study with inclusion of $1 \%$ MWNTs. It is found that nanostructured composite plates have better properties as compared to all other commercial plates.

Fig. 8 shows the $I-V$ performance of composite bipolar plate with $1 \%$ of MWNTs compared with commercial Schunk bipolar plate. I-V performance of bipolar plates was evaluated in a unit fuel cell assembly. The pair of plates is used in unit fuel cell after drawing the flow field channels. The operating temperature is in between 60 and $70{ }^{\circ} \mathrm{C}$ and relative humidity $83 \%$. The flow rate of $\mathrm{H}_{2}$ at anode side was $1.5 \mathrm{lit} \mathrm{min}^{-1}$ and $\mathrm{O}_{2}$ at cathode was 1.0 Lit min ${ }^{-1}$. In unit fuel cell assembly, Nafion-1135 was used as polymer electrolyte membrane of known performance, platinum catalyst and Toray porous conducting carbon paper as gas diffusion layer. The platinum catalyst loaded on anode and cathode side were $0.5 \mathrm{mg} / \mathrm{cm}^{2}$ and $1 \mathrm{mg} \mathrm{cm}^{-2}$ respectively. It is observed that, an open circuit voltage of single cells is almost same at $1.0 \mathrm{~V}$ in both the cases. Nanostructure composite bipolar plate gives the higher power density as compared to commercial schunk bipolar plate. It is clear from Fig. 8, there is difference in the power density value of $100 \mathrm{~mW} / \mathrm{cm}^{2}$ between commercial schunk plate and NPL nanostructure composite plate at current density $1650 \mathrm{~mA} \mathrm{~cm}{ }^{-2}$. Thus, higher power density of MWNTs incorporated bipolar plates ultimately can help in improving fuel cell performance and reduce the stack weight by using less number of plates of higher power density.

\section{Conclusions}

It is found that accumulation of carbon nanotubes in graphite-polymer composite is obliging in improving overall properties. The $1 \mathrm{vol} \%$ of MWNTs is effective in improving conductivity by $100 \%$ and bending strength by $25 \%$. This improvement is due to the MWNTs oriented in all directions and higher value of intrinsic thermal conductivity of MWNTs oriented in z-direction and that facilitate pathway for conduction and heat transfer along the axes direction in through-plane of composite. Higher content of MWNTs does not contribute much in the improvement of mechanical properties of nanocomposite plates due to the lack of dispersion. These results confirm that the optimum content of MWNTs in graphite-polymer composite is 1 vol.\%. These nanostructured graphite composite plates give the higher 
power density which is due to the increase in the electron transfer ability and percolation between graphite particles. These nanostructured composite plates will not only be able to reduce the weight of ultimate stack but also improves the performance of fuel cell as well.

\section{Acknowledgments}

The authors are highly grateful to Prof. R.C. Budhani, Director, NPL (CSIR), for his kind permission to publish the results. The authors would like to thank scientists from CECRI, Chennai center, for evaluating $I-V$ performance of the bipolar plate. Also thanks to Mr. Jai Tawale for providing SEM characterization facilities.

\section{R E F E R E N C E S}

[1] Kinoshita K. Carbons. In: Besenhard JO, editor. Handbook of battery materials. Weinheim: Wiley-VCH; 1999.

[2] Wissler M. Graphite and carbon powders for electrochemical applications. J Power Sources 2006;165:142-50.

[3] Marcinkoski J, Kopasz JP, Benjamin TG. Progress in the US DOE fuel cell subprogram efforts in polymer electrolyte fuel cells. Int J Hydrogen Energy 2008;33:3894-902.

[4] Chalk SG, Miller JF, Wagner FW. Challenges for fuel cells in transport applications. J Power Sources 2000;86:40.

[5] Chen Hui, Liu Hong-Bo, Yang Li, Li Jian-xin, Yang Li. Study on preparation and properties of novaloc epoxy/graphite composite bipolar plate for PEMFC. Int J Hydrogen Energy 2010;35:3105-9.

[6] We M, Shaw LL. A novel concept of carbon filed polymer blends for applications in PEM fuel cell bipolar plates. Int J Hydrogen Energy 2005;30:373-80.

[7] Dhakate SR, Mathur RB, Kakati BK, Dhami TL. Properties of graphite-composite bipolar plate prepared by compression molding technique for PEM fuel cell. Int J Hydrogen Energy 2007;32:4537-43.
[8] Chunbui Shen, Mu Pan, Runzhang Yuan. The effect of particle size gradation of conductive fillers on the conductivity and flexural strength of composite bipolar plate. Int J Hydrogen Energy 2008;33:1035-9.

[9] Dhakate SR, Mathur RB, Sharma S, Borah M, Dhami TL. Influence of expanded graphite particle size on the properties of composite bipolar plate for fuel cell application. Energy \& Fuel 2009;23:934-41.

[10] Iijima S. Helical microtubes of graphic carbon. Nature 1991; 354:56-8.

[11] Dresselhaus M, Avouris P. Carbon nanotubes: synthesis, structure properties and applications. Berlin: Springer; 2001.

[12] Yu M, Files BS, Arepalli S, Ruoff RS. Tensile loading of ropes of single wall carbon nanotubes and their mechanical properties. Phys Rev Lett 2000;84:5552-5.

[13] Yu M, Lourie O, Dyer MJ, Moloni K, Kelly TF, Ruoff RS. Strength and breaking mechanism of multiwalled carbon nanotubes under tensile load. Science 2000;287:637-40.

[14] Fang W, Chu HY, Hsu WK, Cheng TW, Tai NH. Polymerreinforced, alligned multiwalled carbon nanotube composites for microelectromechanical systems applications. Adv Mater 2005;17:2987-96.

[15] Ajayan PM, Stephan O, Colliex C, Trauth D. Aligned carbon nanotubes arrays formed by cutting a polymer resinnanotube composite. Science 1994;265:1212-4.

[16] Mathur RB, Chatterjee S, Singh BP. Growth of carbon nanotubes on different carbon substrates and their use as reinforcement in polymer composites. Compos Sci Technol 2008;68:1608-15.

[17] Dhakate SR, Sharma S.Borah M, Mathur RB, Dhami TL. Expanded graphite- based electrically conductive composites as bipolar plate fro PEM fuel cell. Int J Hydrogen Energy 2007; 32:4537-43.

[18] Wolf H, Willert-Porada M. Electrically conductive LCP carbon composite with low carbon content for bipolar plate application in PEMFC. J Power Sources 2006;153:41-6.

[19] http://www1.eere.energy.gov/hydrogenandfuelcells/mypp/ pdfs/fuelcells.pdf,website; 2007.

[20] http://www.sglcarbon/FuelCellComponents.

[21] http://sgroup.cms.schunk-group.com/sixcms/media.php/ 543/brochure-with-datasheet.pdf.

[22] http://www.fuelcellstore.com/cgi-bin/fuelweb/view=Item/ cat $=/$ product $=594$. 